\title{
Neurodevelopmental Disorders Induced by Maternal Immune Activation: Toward a Prevention Strategy in the Era of the COVID-19 Pandemic
}

\author{
Kazuhiro Sakurada ${ }^{1, *}$ and Yoshihiro Noda ${ }^{2, *(D)}$ \\ 1 Healthcare and Medical Data Multi-level Integration Platform Group, Medical Sciences Innovation \\ Hub Program, RIKEN, Tokyo 103-0027, Japan \\ 2 Multidisciplinary Translational Research Lab, Department of Neuropsychiatry, Keio University \\ School of Medicine, Tokyo 160-8582, Japan \\ * Correspondence: kazuhiro.sakurada@riken.jp (K.S.); yoshi-tms@keio.jp (Y.N.)
}

Received: 4 August 2020; Accepted: 14 August 2020; Published: 18 August 2020

\begin{abstract}
As of summer 2020, the COVID-19 pandemic is having a major impact on our daily lives on a global scale, forcing us to change to the new normal. However, the effects are not only detrimental to our present socioeconomic conditions but also have the risk of having negative biological effects on our descendants. Of concern is the effect of maternal immune activation following maternal infection with COVID-19 on the fetus' cerebral nervous system. While we are currently occupied with countering the imminent threats in front of us, we also need to take steps from a public health perspective to reduce the impact of maternal infection on the fetus, especially the risk of neurodevelopmental disorders. However, such a risk can be prevented and managed through the digital transformation of the nation's health data and the strategic application of sophisticated data science approaches to those big data.
\end{abstract}

Keywords: maternal immune activation; neurodevelopmental disorders; SARS-CoV-2

\section{Introduction}

In 1918, the appearance of influenza H1N1 caused lethal flu all over the world. Although the pandemic lasted only a few years, its negative impacts lasted for a long time. Cohort studies in the United States indicated that the offspring of women who were pregnant during the 1918 pandemic displayed increased rates of physical disability, lower incomes, lower socioeconomic status, and reduced educational attainment [1]. Furthermore, similar impacts were reported from cohort studies in Sweden [2].

\section{Association between Maternal Infection and Psychiatric Disorders}

Epidemiological studies have indicated a strong association between maternal infection and mental disorders including autism spectrum disorder (ASD), schizophrenia, and mood disorders [3]. In the 1964 rubella pandemic, maternal infection significantly increased the incidence of ASD and schizophrenia from less than $1 \%$ in the uninfected population to $13 \%$ and $20 \%$, respectively, in the infected population [4]. In addition to influenza and rubella, herpes simplex virus type 2, cytomegalovirus, Toxoplasma gondii, and bacterial infections during pregnancy are associated with the risk of developing ASD and schizophrenia [3].

\section{Changes in the Concept of Autism}

On the other hand, among the neurodevelopmental disorders, the most muddled concept is ASD. In the landmark 1943 paper, Leo Kanner took the term "autism" — which was previously attributed to 
the inward, introspective symptoms typically seen in adult patients with schizophrenia [5]. In 1944, Hans Asperger identified a pattern of behaviors and abilities that included "a lack of empathy, little ability to form friendships, one-sided conversations, intense absorption in a special interest, and clumsy movements" [6]. Indeed, individuals with ASD often show impairment of the higher brain functions such as interpersonal cognition, communication skills, and/or motor coordination, and these symptoms last throughout a lifetime because there are no effective treatments currently available for the core symptoms and characteristics of ASD. Furthermore, the recent drastic increase in the ASD population, which cannot be explained by genetic factors alone, has gone beyond psychiatric problems and has now become a social problem affecting employment and social adjustment.

\section{Maternal Immune Activation as a Potential Pathological Basis for Neurodevelopmental Disorders}

Neurodevelopmental disorders have been historically categorized according to their clinical phenotype. However, it has been suggested that ASD, attention deficit hyperactivity disorder, learning disorder, and developmental coordination disorder are also linked to each other in the same child, indicating that these neurodevelopmental disorders may have a shared neural base caused by common causes. In other words, maternal immune activation may be involved in the background of one of the common pathological bases for neurodevelopmental disorders. For example, interleukin-6 and -17 are transmitted through the placenta and induce inflammation in the fetal brain, which, in turn, alters interneuron differentiation, synaptic formation and pruning, and myelination [7].

\section{Modifiable Factors That Reduce the Risk of Neurodevelopmental Disorders}

Multiple factors are involved in the development of neurodevelopmental disorders, including genetic factors, fetal health status, the maternal environment at birth, infectious diseases, and the external environment; however, one of the most modifiable factors is maternal infection prevention. In this context, the risk of infections during pregnancy can be reduced by specific dietary ingredients, for example, vitamin D [8]. Most of the vitamin D is generated by exposure to sunlight. In Japan, many women are deficient in vitamin $\mathrm{D}$ due to excessive fear of the side effects of ultraviolet radiation [9]. Viruses replicate more efficiently during the winter season, caused by a seasonal fluctuation of immune function [10]. In the coming winter, the reduction of sun exposure and efficient viral replication could have detrimental effects in the Northern Hemisphere.

\section{Conclusions}

Currently, there is insufficient information on the relationship between maternal infection with SARS-CoV-2 and neurodevelopmental disorders. Thus, it is an urgent issue to develop personalized medicine to prevent and detect the occurrence of neurodevelopmental disorders induced by maternal immune activation. For this purpose, data-driven studies integrating data from clinical measures, multi-omics analyzers, and wearable biomedical sensors will become increasingly essential in the future. Disease is the process of "becoming" ill. Therefore, the reductionist approach has its limitations in explaining such temporal developments. An alternative approach is to analyze lifelog data by applying techniques such as information geometry and complex systems science [11]. Progress in machine learning and deep learning technologies will surely help to solve these challenges.

Author Contributions: Conceptualization, K.S.; writing — original draft preparation, K.S. and Y.N.; writing—review and editing, Y.N. All authors have read and agreed to the published version of the manuscript.

Funding: K.S. has received a grant for the Society 5.0 Realization Research Support Project from the Ministry of Education, Culture, Sports, Science and Technology (MEXT) and Innovation Hub Construction Support from the Japan Science and Technology Agency (JST). Y.N. has received a Grant-in-Aid for Young Scientists (KAKENHI) from the Promotion of Science, research grants from the Japan Agency for Medical Research and Development (AMED), and investigator-initiated clinical study grants from TEIJIN PHARMA LIMITED and Inter Reha Co., Ltd. Y.N. also receives research grants from the Japan Health Foundation, Meiji Yasuda Mental Health Foundation, Mitsui Life Social Welfare Foundation, Takeda Science Foundation, SENSHIN Medical Research Foundation, Health Science Center Foundation, Mochida Memorial Foundation for Medical and Pharmaceutical 
Research, Taiju Life Social Welfare Foundation, and Daiichi Sankyo Scholarship Donation Program. Y.N. has received speaker's honoraria from Dainippon Sumitomo Pharma, MOCHIDA PHARMACEUTICAL CO., LTD., and Yoshitomiyakuhin Corporation within the past three years. Y.N. also receives equipment-in-kind support for an investigator-initiated study from Magventure Inc, Inter Reha Co., Ltd., Rogue Resolutions Ltd., and Miyuki Giken Co., Ltd.

Acknowledgments: We are most grateful to Seiichi Morokuma and the late Yukuo Konishi for his suggestion on maternal immune activation and neurodevelopmental disorders.

Conflicts of Interest: The authors declare no conflict of interest.

\section{References}

1. Almond, D. Is the 1918 influenza pandemic over? Long-term effects of in utero influenza exposure in the post-1940 U.S. population. J. Polit. Econ. 2006, 114, 672-712. [CrossRef]

2. Helgertz, J.; Bengtsson, T. The long-lasting influenza: The impact of fetal stress during the 1918 influenza pandemic on socioeconomic attainment and health in Sweden, 1968-2012. Dermography 2019, 56, 1389-1425. [CrossRef] [PubMed]

3. Knuesel, I.; Chicha, L.; Britschgi, M.; Schobel, S.A.; Bodmer, M.; Hellings, J.A.; Toovey, S.; Prinssen, E.P. Maternal Immune Activation and Abnormal Brain Development Across CNS Disorders. Nat. Rev. Neurol. 2014, 10, 643-660. [CrossRef]

4. Patterson, P.H. Immune Involvement in Schizophrenia and Autism: Etiology, Pathology and Animal Models. Behav. Brain Res. 2009, 204, 313-321. [CrossRef]

5. Kanner, L. Autistic Disturbances of Affective Contact. Acta Paedopsychiatr. 1968, 35, 100-136. [PubMed]

6. Asperger, H. Die "Autistischen Psyuchopathen" im Kindesalter. Arch. Fur Psyciatrie Und Nervenkrankh. 1944, 117, 76-136. [CrossRef]

7. Wong, H.; Hoeffer, C. Maternal IL-17A in Autism. Exp. Neurol. 2018, 299, 228-240. [CrossRef] [PubMed]

8. Cannell, J.J. Vitamin D and Autism, What's New? Rev. Endocr. Metab. Disord. 2017, 18, 183-193. [CrossRef] [PubMed]

9. Kanatani, K.T.; Nakayama, T.; Adachi, Y.; Hamazaki, K.; Onishi, K.; Konishi, Y.; Kawanishi, Y.; Go, T.; Sato, K.; Kurozawa, Y.; et al. Japan Environment and Children's Study Group. High Frequency of Vitamin D Deficiency in Current Pregnant Japanese Women Associated with UV Avoidance and Hypo-Vitamin D Diet. PLoS ONE 2019, 14, e0213264. [CrossRef] [PubMed]

10. Dopico, X.C.; Evangelou, M.; Ferreira, R.C.; Guo, H.; Pekalski, M.L.; Smyth, D.J.; Cooper, N.; Burren, O.S.; Fulford, A.J.; Hennig, B.J.; et al. Widespread seasonal gene expression reveals annual differences in human immunity and physiology. Nat. Commun. 2015, 6, 7000. [CrossRef] [PubMed]

11. Nock, R.; Polouliakh, N.; Nielsen, F.; Oka, K.; Connell, C.R.; Heimhofer, C.; Shibanai, K.; Ghosh, S.; Aisaki, K.I.; Kitajima, S.; et al. Geometric Clustering Tool (AGCT) to robustly unravel the inner cluster structures of time-series gene expressions. PLoS ONE 2020, 15, e0233755. [CrossRef] [PubMed]

(C) 2020 by the authors. Licensee MDPI, Basel, Switzerland. This article is an open access article distributed under the terms and conditions of the Creative Commons Attribution (CC BY) license (http://creativecommons.org/licenses/by/4.0/). 